\title{
The Practice of Nuclear Pharmacy Services by Pharmacists in Saudi Arabia
}

\author{
Yousef Ahmed Alomi*, (D) Bsc. \\ Pharm, Msc. Clin pharm, BCPS, BCNSP, \\ Critical Care Clinical Pharmacists, TPN Clinical \\ Pharmacist, Freelancer Business Planner, \\ Content Editor, and Data Analyst, Riyadh, \\ SAUDI ARABIA.
}

Ali Taer Al-Asmri, BSc.Pharm, Al-Dawaa Medical Services Co. LTD, Abha,

SAUDI ARABIA.

Mohammed Abdulaziz Ayoub

Asiri, BSc. Pharm, Dr. Sulaiman Alhabib

Medical Group, Riyadh, SAUDI ARABIA.

Abdulaziz Saleh Alnabbah, Bsc. Pharm, Riyadh, SAUDI ARABIA.

\section{Correspondence:}

Dr. Yousef Ahmed Alomi, Bsc. Pharm, Msc. Clin pharm, BCPS, BCNSP, DiBA, CDE Critical Care Clinical Pharmacists, TPN Clinical Pharmacist, Freelancer Business Planner, Content Editor and Data Analyst, P.O.BOX 100, Riyadh 11392, Riyadh, SAUDI ARABIA.

Phone no: +966 504417712

E-mail:yalomi@gmail.com

Received: 10-11-2020;

Accepted: 17-1-2021;

Copyright: $\odot$ the author(s), publisher and licensee International Journal of Pharmacology and Clinical Sciences. This is an open-access article distributed under the terms of the Creative Commons

Attribution Non-Commercial License, which permits unrestricted non-commercial use, distribution, and reproduction in any medium, provided the original work is properly cited.

This is an open access article distributed under the terms of the Creative Commons AttributionNonCommercial-ShareAlike 4.0 License

Access this article online

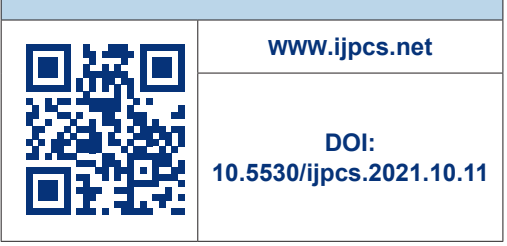

\section{ABSTRACT}

Goal: In this study, we aimed to illustrate the practice of nuclear pharmacy services in Saudi Arabia. Methods: This is a cross-sectional study. An electronic survey was distributed to all pharmacists and pharmacy interns. Students were excluded from this study. The survey consisted of demographic data about responders and pharmacy practice aspects of nuclear pharmacy. The data were collected using the Survey Monkey system and analyzed using Microsoft Excel and Statistical Package of Social Science (SPSS). Results: A total of 235 pharmacists responded to the survey, with most of them coming from the southern region (82 (34.89\%)), central region $(49(20.85 \%))$, and western region $(47(20.00 \%))$, with statistically significant differences between the regions $(p<0.001)$. Almost two-thirds of the pharmacists had obtained Bachelor's degree (149 (63.40\%)) and Diploma in Pharmacy (75 (31.91\%)), with statistically significant differences between all the pharmaceutical degrees $(p<0.001)$. Most pharmacists were staff pharmacists $(119(51.29 \%))$ and interns $(43(18.53 \%))$. The total average score of elements of the practice of nuclear pharmacy services was 1.69. The highest score was recorded for the element "nuclear pharmacy and facilities, equipment, and place for preparation are available" (1.79), followed by the elements "nuclear pharmacy and drug monitoring system" (1.78) and "nuclear pharmacy and radiation safety" (1.77). The average score for the element "nuclear pharmacy practice implementation" was 3.39. High scores were obtained for the element "nuclear pharmacy should be covered by health insurance" (3.79) and "nuclear pharmacy outsourcing is highly recommended" (3.67). The highest score was obtained for the element "nuclear pharmacy currently is the responsibility was a nuclear pharmacist" (4.28) and "toxicologist laboratory" (3.55). Conclusion: The various aspects of pharmacists based on the elements of the practice implementation of nuclear pharmacy were insufficient in the Kingdom of Saudi Arabia. Pharmacists play an active role in the nuclear pharmacy practice. Further studies on nuclear pharmacy services should be conducted thoroughly and setup strategic plan to improve nuclear pharmacy services in Saudi Arabia.

Keywords: Practice, Pharmacist, Nuclear, Pharmacy, Saudi Arabia.

\section{INTRODUCTION}

The pharmacist at the hospital pharmacy prepares, dispenses, and monitors various medications, including common drugs, chemotherapeutic agents, and radioactive medicines (radioactive pharmaceutical products). They are administered in different dosage forms, either orally or topically, and via parenteral medications. Each type of nuclear medicine has specific regulations for its process of distribution. For example, in parenteral medicines, the pharmacist should follow 797 United Stare Pharmacopeia (USP) guidelines; $;^{[1,2]}$ for chemotherapy, the pharmacist should implement 800 USP, ${ }^{[3,4]}$ and radiopharmaceutical products should be distributed through 825 USP regulations. ${ }^{[5]}$ All those specific infrastructures in the pharmacy design and during drug distribution are needed. Locally, preparation and dispensing of various radioactive materials have been required by the Saudi Food and Drug Authority, and other international radiopharmaceutical preparation and dispensing and needs to be followed and implemented. ${ }^{[2,6-9]}$ In addition, nuclear pharmacists dealing with radiopharmaceutical products should be registered through the National Boards of Pharmacy. ${ }^{[10]}$

The nuclear pharmacy system foundation needs a clear definition of radioactive material, vision, mission, and objectives. Moreover, all requirements of safe handling, pharmacist and patient safety considerations, and total quality management of radiopharmaceutical agents in the nuclear pharmacy practice domains must be implemented. ${ }^{[5,11]}$ Various studies have been conducted to explore the general practice of nuclear medicine in multiple countries, including Saudi Arabia. ${ }^{[12-14]}$ However, only a few studies are conducted on nuclear pharmacy practice. ${ }^{[15,16]}$ A previous study explored the employment condition and workload of nuclear pharmacists. [17] Several other studies have investigated the participation of pharmacists in nuclear medicine services. ${ }^{[12,13,16,18]}$ However, no in-depth studies are conducted on nuclear pharmacy practice either locally or in Gulf and Middle Eastern countries. Therefore, in this study, our goal was to explore the pharmacist practice of nuclear pharmacy in the Kingdom of Saudi Arabia. 


\section{METHOD}

This is a cross-sectional survey conducted to analyze the practice of nuclear pharmacy by pharmacists in Saudi Arabia. This is a self-reported questionnaire distributed electronically to dentists, pharmacists (from interns to consultants), and pharmacy specialists in Saudi Arabia. All non-pharmacists and students and incomplete surveys were excluded from this study. The survey collected demographic information of the responders and their knowledge of selected nuclear pharmacy practice elements in pharmaceutical care. The nuclear pharmacy responsibility and nuclear pharmacy practice implementation. In this study, we used the 5-point Likert response scale system with close-ended questions to obtain responses. The sample size was calculated based on the available literature for a cross-sectional study; we applied a confidence level of $95 \%$ with a $z$ score of 1.96 and margin of error of 5-6.5\%, the population percentage of $50 \%$, and a drop-out rate of $10 \%$. With these parameters, the sample size was calculated as 251 to 432 , with a power of study of $80 \% \cdot{ }^{[19-21]}$ The minimum response rate that might be required for the calculated sample size was at least $60-70 \%{ }^{[21,22]}$ The survey was distributed via WhatsApp and Telegram groups of pharmacists. A reminder message was sent once every 1-2 weeks. The expert reviewers and pilot testing validated the survey. Furthermore, various reliability tests such as McDonald's $\omega$, Cronbach's $\alpha$, Gutmann's $\lambda 2$, and Gutmann's $\lambda 6$ were used to test the reliability of the data. The data were captured through the Survey Monkey system, analyzed by the Statistical Package of Social Sciences (SPSS) software, Jeffery's Amazing Statistics Program (JASP), Microsoft Excel version 16. The descriptive and frequency analysis with the goodness of fit, correlation analysis, and inferential analysis of factors was conducted to analyze pharmacists' knowledge of medication safety. The STROBE (strengthening the reporting of observational studies in epidemiology statement: guidelines for reporting observational studies) guided the reporting of this study. ${ }^{[23,24]}$

\section{RESULTS}

A total of 235 pharmacists responded to the survey, with most of them coming from the southern region (82 $(34.89 \%))$, central region $(49(20.85 \%))$, and the western region (47 (20\%)), with statistically significant differences between the areas $(p<0.001)$. Of them, $142(63.96 \%)$ responders were male, and $80(36.04 \%)$ were female, with statistically significant differences between them $(p<0.001)$. Most of the responders were in the age group of $24-30$ years $(115(48.94 \%))$ and
31-35 years $(57(24.26 \%))$, with statistically significant differences between all ages groups $(p<0.001)$. Almost two-thirds of the pharmacists had obtained Bachelor's degree (149 (63.40\%)) and Diploma in Pharmacy (75 (31.91\%)), with statistically significant differences among all pharmaceutical degrees $(p<0.001)$. Most pharmacists were staff pharmacists (119 (51.29\%)) and interns (43 (18.53\%)). Most of the responders had a work experience of 3 years and less (124 $(52.99 \%))$, with the majority of them having experience at the outpatient pharmacy (26 (29.89\%)) and inpatient pharmacy (19 (21.84\%)), with statistically significant differences between them $(p<0.001)$. There was a strong positive correlation between age (years) and years of experience at pharmacy centers based on Kendall's tau_b (0.705) or Spearman's rho (0.784) values, with statistically significant differences between them $(p>0.05)$. However, there is a medium negative correlation between position and years of experience at pharmacy career Kendall's tau_b $(-0.505)$ or Spearman's rho $(-0.592)$ with statistically significant differences between them $(p>0.05)$ (Table 1 and 2).

The total average score of the element "practice of nuclear pharmacy services" was 1.69. High scores were obtained for the aspect "nuclear pharmacy and facilities, equipment, and place for preparation are available" (1.79), followed by "nuclear pharmacy and drug monitoring system" (1.78), "nuclear pharmacy and radiation safety" (1.77), and "nuclear pharmacy and chemical weapon" (1.77). However, low scores were obtained for the elements "nuclear pharmacy was the vision of nuclear pharmacy" (1.4), the mission of nuclear pharmacy (1.58), and the annual plan of nuclear pharmacy (1.61), with statistically significant differences between answers $(p<0.001)$ (Table 3$)$. The average score for the element "nuclear pharmacy practice implementation" was (3.39). High scores were obtained for the aspect "nuclear pharmacy should be covered by health insurance" (3.79), "the nuclear pharmacy outsourcing is highly recommended" (3.67), and "the clinical pharmacist had an active role in nuclear medicine departments" (3.56). However, the elements "nuclear pharmacy practice implementation scores were attendance several courses or workshops about nuclear pharmacy" (2.9) and "there are various nuclear pharmacy resources in practice available" (3.09) obtained low scores. In addition, the average score for the element "there is an electronic nuclear pharmacy connected with an electronic prescription, or computerized physicians order enter" was (3.22), with statistically significant

\begin{tabular}{|c|c|c|c|}
\hline Nationality & Response Count & Response Percent & $p$-value (X2) \\
\hline Central area & 49 & $20.85 \%$ & \multirow[t]{5}{*}{$<0.001$} \\
\hline North area & 32 & $13.62 \%$ & \\
\hline South area & 82 & $34.89 \%$ & \\
\hline East area & 25 & $10.64 \%$ & \\
\hline West area & 47 & $20.00 \%$ & \\
\hline Answered question & 235 & & \\
\hline Skipped question & 0 & & \\
\hline Gender & Response Count & Response Percent & \\
\hline Male & 142 & $63.96 \%$ & \multirow[t]{2}{*}{$<0.001$} \\
\hline Female & 80 & $36.04 \%$ & \\
\hline Answered question & 222 & & \\
\hline Skipped question & 13 & & \\
\hline Age & Response Count & Response Percent & \\
\hline $24-30$ & 115 & $48.94 \%$ & \multirow[t]{6}{*}{$<0.001$} \\
\hline $31-35$ & 57 & $24.26 \%$ & \\
\hline $36-40$ & 34 & $14.47 \%$ & \\
\hline $41-45$ & 10 & $4.26 \%$ & \\
\hline $46-50$ & 11 & $4.68 \%$ & \\
\hline$>50$ & 8 & $3.40 \%$ & \\
\hline Answered question & 235 & & \\
\hline Skipped question & 0 & & \\
\hline
\end{tabular}




\begin{tabular}{|c|c|c|c|}
\hline Pharmacist Qualifications & Response Count & Response Percent & $p$-value (X2) \\
\hline Diploma in Pharmacy & 14 & $5.96 \%$ & \\
\hline Bachelor's in pharmacy & 149 & $63.40 \%$ & \\
\hline Master & 41 & $17.45 \%$ & \\
\hline Pharm D & 75 & $31.91 \%$ & \\
\hline $\mathrm{Ph} . \mathrm{D}$ & 23 & $9.79 \%$ & \\
\hline PGY 1 & 10 & $4.26 \%$ & \\
\hline PGY 2 & 5 & $2.13 \%$ & \\
\hline PGY 3 & 6 & $2.55 \%$ & \\
\hline Fellowship & 1 & $0.43 \%$ & \\
\hline Other (please specify) & 1 & $0.43 \%$ & \\
\hline Answered question & 235 & & \\
\hline Skipped question & $\mathbf{0}$ & & \\
\hline Position Held & Response Count & Response Percent & \\
\hline Director of Pharmacy & 16 & $6.90 \%$ & \multirow[t]{5}{*}{$<0.001$} \\
\hline Assistant Director of Pharmacy & 18 & $7.76 \%$ & \\
\hline Supervisor & 36 & $15.52 \%$ & \\
\hline Pharmacy staff & 119 & $51.29 \%$ & \\
\hline Pharmacy Intern & 43 & $18.53 \%$ & \\
\hline Answered question & 232 & & \\
\hline Skipped question & 3 & & \\
\hline Years of experience at Physician career & Response Count & Response Percent & \\
\hline Less than one year & 56 & $23.93 \%$ & \multirow[t]{6}{*}{$<001$} \\
\hline $1-3$ & 68 & $29.06 \%$ & \\
\hline $4-6$ & 45 & $19.23 \%$ & \\
\hline $7-9$ & 32 & $13.68 \%$ & \\
\hline $10-12$ & 13 & $5.56 \%$ & \\
\hline$>12$ & 20 & $8.55 \%$ & \\
\hline Answered question & 234 & & \\
\hline Skipped question & 1 & & \\
\hline The practice area & Response Count & Response Percent & \\
\hline Inpatient Pharmacy & 19 & $21.84 \%$ & \multirow[t]{11}{*}{$<001$} \\
\hline Outpatient Pharmacy & 26 & $29.89 \%$ & \\
\hline Satellite Pharmacy & 1 & $1.15 \%$ & \\
\hline Narcotics and Controlled & 3 & $3.45 \%$ & \\
\hline Extemporaneous Preparation & 1 & $1.15 \%$ & \\
\hline Clinical Pharmacy & 10 & $11.49 \%$ & \\
\hline Inventory Control & 1 & $1.15 \%$ & \\
\hline Drug Information & 2 & $2.30 \%$ & \\
\hline IV admixture & 1 & $1.15 \%$ & \\
\hline Community pharmacy & 9 & $10.34 \%$ & \\
\hline Pharmaceutical companies & 7 & $8.05 \%$ & \\
\hline Other (please specify) & 7 & $8.05 \%$ & \\
\hline Answered question & 87 & & \\
\hline Skipped question & 148 & & \\
\hline
\end{tabular}

differences between the responses $(p<0.001)$ (Table 4). The scores for the elements "nuclear pharmacy (to authorities) is currently the responsibility of a nuclear pharmacist" (4.28), and for "toxicologist laboratory," it was (3.55). In contrast, the lowest score was nuclear medicine doctor (2.38), with a statistically significant difference between all answers $(p<0.001)$ (Table 5). The majority of the responders work in a nuclear pharmacy (208 (89.27\%)). However, there were no statically significant differences between all responders who worked or did not work in nuclear pharmacy practice $(p>0.05)$. The reliability test of McDonald's $\omega$, (0.917), Cronbach's $\alpha(0.943)$, Gutmann's $\lambda 2$ (0.950), and Gutmann's $\lambda 6$ (0.977).

\section{Factors (average scores) influencing the items for nuclear pharmacy practice and nuclear pharmacy implementation}

Various factors might influence the items for nuclear pharmacy practice in the Kingdom of Saudi Arabia. For example, the location of the pharmacist affected the knowledge about nuclear pharmacy implementation, with the western region scoring the lowest average (1.3313). There were statically significant differences between the responses from the different areas $(p=0.001)$. There were no statically significant differences found in other age groups $(p=0.075)$, gender $(p=0.617)$, position $(p=0.391)$, and years of experience ( $p=0.336)$. Furthermore, various factors might influence the nuclear pharmacy implementation in the Kingdom of Saudi Arabia. For example, different locations affected implementation knowledge, with the highest average score (3.8537) with statically significant differences between them $(p=0.001)$. The implementation of nuclear pharmacy was affected by age groups (24-30 years showed the lowest average score (3.2058) and 31-36 years with the score of (3.2582), with statically significant differences them $(p=0.000)$. Gender of the pharmacist affected the score for nuclear pharmacy implementation, with the highest score obtained for females (3.5705), with statistically significant differences $(p=0.04)$. The position of the pharmacist affected the implementation of nuclear pharmacy; the pharmacy supervisor had the highest average score (3.8402), with statically significant differences $(p=0.003)$. Years of work experience also affected the nuclear pharmacy implementation, with pharmacists with 10-12 years of experience having the highest average score (4.3765), with statically significant differences between them $(p=0.003)$ (Table 6).

In this study, we analyzed the relationship between the practice aspect of nuclear 


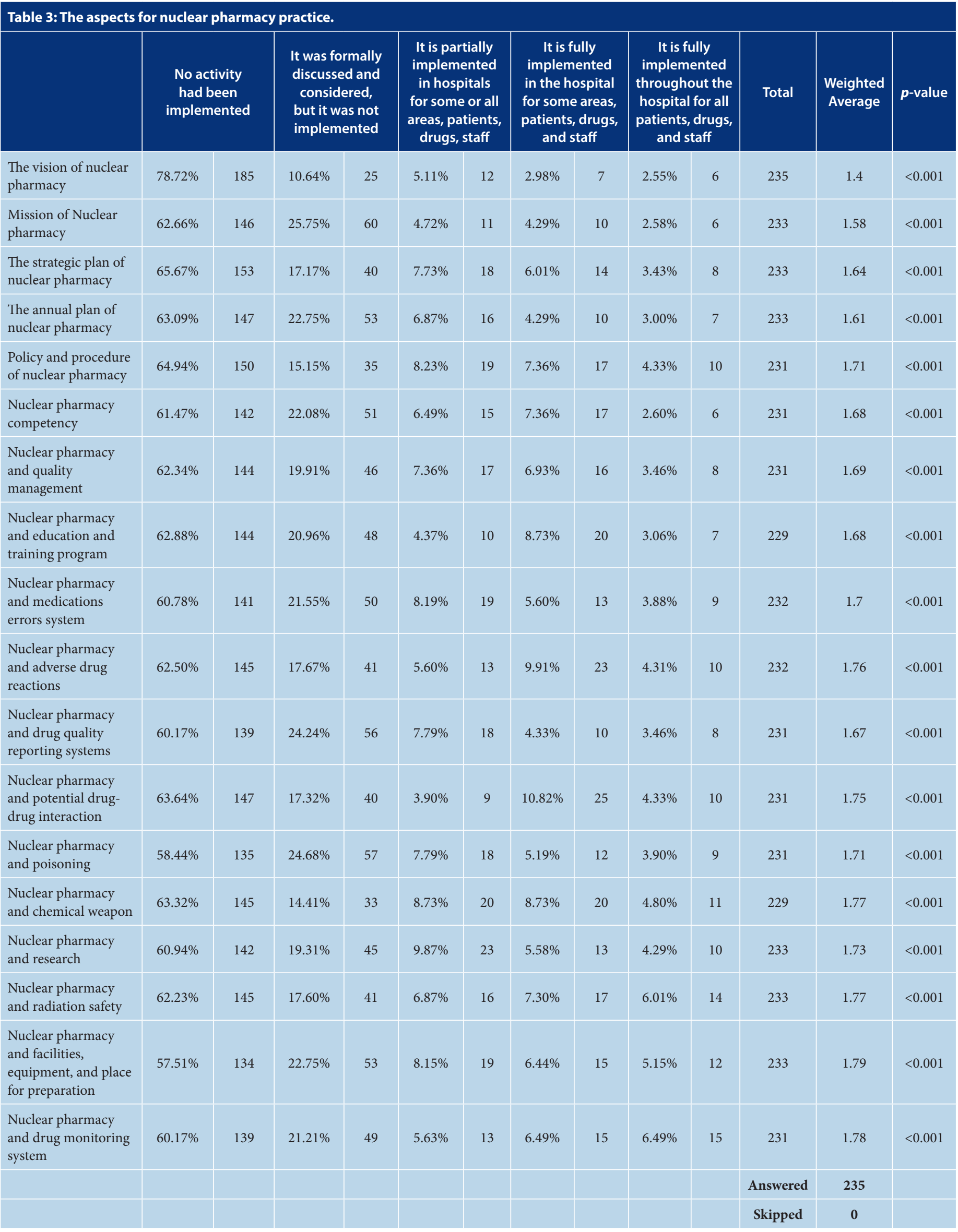




\begin{tabular}{|c|c|c|c|c|c|c|c|c|c|c|c|c|c|}
\hline $\begin{array}{l}\text { The pharmacist share in } \\
\text { nuclear medicine committee }\end{array}$ & \multicolumn{2}{|c|}{$\begin{array}{l}\text { Strongly } \\
\text { disagree }\end{array}$} & \multicolumn{2}{|c|}{ Disagree } & \multicolumn{2}{|c|}{ Uncertain } & \multicolumn{2}{|c|}{ Agree } & \multicolumn{2}{|c|}{ Strongly agree } & $\begin{array}{l}\text { Total } \\
234\end{array}$ & $\begin{array}{c}\text { Weighted } \\
\text { Average } \\
3.53\end{array}$ & $<0.001$ \\
\hline $\begin{array}{l}\text { The pharmacist always a staff } \\
\text { member of nuclear medicine } \\
\text { departments }\end{array}$ & $6.90 \%$ & 16 & $9.91 \%$ & 23 & $33.62 \%$ & 78 & $21.98 \%$ & 51 & $27.59 \%$ & 64 & 232 & 3.53 & $<0.001$ \\
\hline $\begin{array}{l}\text { The clinical pharmacist } \\
\text { had active role in nuclear } \\
\text { medicine departments }\end{array}$ & $8.70 \%$ & 20 & $9.13 \%$ & 21 & $27.83 \%$ & 64 & $26.09 \%$ & 60 & $28.26 \%$ & 65 & 230 & 3.56 & $<0.001$ \\
\hline $\begin{array}{l}\text { I attended several courses } \\
\text { or workshops about nuclear } \\
\text { pharmacy }\end{array}$ & $22.41 \%$ & 52 & $17.24 \%$ & 40 & $25.00 \%$ & 58 & $18.97 \%$ & 44 & $16.38 \%$ & 38 & 232 & 2.9 & 0.192 \\
\hline $\begin{array}{l}\text { There is electronic nuclear } \\
\text { pharmacy }\end{array}$ & $12.50 \%$ & 29 & $9.91 \%$ & 23 & $39.22 \%$ & 91 & $19.83 \%$ & 46 & $18.53 \%$ & 43 & 232 & 3.22 & $<0.001$ \\
\hline $\begin{array}{l}\text { There are various of nuclear } \\
\text { pharmacy resources in the } \\
\text { practice }\end{array}$ & $14.96 \%$ & 35 & $15.81 \%$ & 37 & $32.48 \%$ & 76 & $18.38 \%$ & 43 & $18.38 \%$ & 43 & 234 & 3.09 & $<0.001$ \\
\hline $\begin{array}{l}\text { The nuclear medicine } \\
\text { departments are responsible } \\
\text { of procurement, preparation, } \\
\text { and dispensing radio } \\
\text { pharmaceutical products }\end{array}$ & $9.01 \%$ & 21 & $13.73 \%$ & 32 & $37.34 \%$ & 87 & $19.31 \%$ & 45 & $20.60 \%$ & 48 & 233 & 3.29 & $<0.001$ \\
\hline $\begin{array}{l}\text { The nuclear pharmacy } \\
\text { should be covered by health } \\
\text { insurance }\end{array}$ & $5.17 \%$ & 12 & $8.62 \%$ & 20 & $25.43 \%$ & 59 & $23.71 \%$ & 55 & $37.07 \%$ & 86 & 232 & 3.79 & $<0.001$ \\
\hline \multirow{3}{*}{$\begin{array}{l}\text { I think the nuclear pharmacy } \\
\text { outsourcing is high } \\
\text { recommended }\end{array}$} & $6.87 \%$ & 16 & $9.87 \%$ & 23 & $25.75 \%$ & 60 & $24.46 \%$ & 57 & $33.05 \%$ & 77 & 233 & 3.67 & $<0.001$ \\
\hline & & & & & & & & & & & Answered & 235 & \\
\hline & & & & & & & & & & & Skipped & $\mathbf{0}$ & \\
\hline
\end{tabular}

pharmacy and factors affecting it, such as location, age (years), gender, position held, and years of experiences of the pharmacist at the pharmacy center. This relationship was demonstrated through a multiple regression model. In the model, the practice aspect of nuclear pharmacy was considered the dependent variable, and factors affecting it were regarded as an expletory variable. Our analysis showed a weak relationship $(\mathrm{R}=0.261$ with $p=0.010)$ between the implementation of nuclear pharmacy and factors affecting it. However, only two factors affected the responses: first, the location of the pharmacist explained $17.2 \%(p=0.010)$ of the variation in the negative relationship, and second, age of the pharmacists explained $41.6 \% \quad(p=0.000)$ of the variation in the positive relationship between the practice of nuclear pharmacy implementation with a statistically significant $(p<0.05)$ through multiple regression model. The bootstrap model confirmed it. The relationship between the practice aspect of nuclear pharmacy and the two factors was verified by the nonexistence of multicollinearity with location factor $(\mathrm{VIF}=1.053)$ and age $(\mathrm{VIF}=3.11)$, all of them almost less than three or less than five ${ }^{[25-27]}$ (Table 7).

Next, we studied the relationship between the practice of implementing nuclear pharmacy and factors affecting it, such as location, age (years), gender, position held, and years of pharmacist experience at the pharmacy center. This relationship was demonstrated through the multiple regression model by considering the implementation of nuclear pharmacy as the -dependent variable and factors affecting it as the expletory variable. Our analysis showed a weak relationship $(\mathrm{R}=0.373$ with 


\begin{tabular}{|l|l|l|l|l|l|l|l|l|l|l|l|}
\hline & Table 5: The nuclear pharmacy (to authorities) currently is the responsibility of the following. \\
\hline & Strongly disagree & \multicolumn{2}{|c|}{ Disagree } & Uncertain & Agree & Strongly agree & $\begin{array}{c}\text { Weighted } \\
\text { Average }\end{array}$ & Total \\
\hline
\end{tabular}

\begin{tabular}{|c|c|c|c|c|c|c|c|c|c|c|c|c|c|c|c|}
\hline & \multirow[b]{2}{*}{ Factors } & \multicolumn{7}{|c|}{ Aspects for nuclear pharmacy practice } & \multicolumn{7}{|c|}{ nuclear pharmacy implementation } \\
\hline & & $\mathrm{N}$ & $\begin{array}{c}\text { Average } \\
\text { scores }\end{array}$ & Std. D & Median & $\begin{array}{l}\text { Lower } \\
\text { Bound }\end{array}$ & $\begin{array}{l}\text { Upper } \\
\text { Bound }\end{array}$ & $P$-value & $\mathbf{N}$ & $\begin{array}{l}\text { Average } \\
\text { scores }\end{array}$ & Std. D & Median & $\begin{array}{l}\text { Lower } \\
\text { Bound }\end{array}$ & $\begin{array}{l}\text { Upper } \\
\text { Bound }\end{array}$ & $P$-value \\
\hline \multirow{6}{*}{ 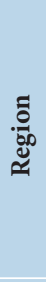 } & Central & 46 & 1.7105 & .99515 & 1.3611 & 1.4149 & 2.0060 & \multirow{5}{*}{0.001} & 46 & 3.0703 & .94990 & 3.0417 & 2.7882 & 3.3524 & \multirow{5}{*}{0.001} \\
\hline & North & 28 & 2.0754 & .78687 & 2.1667 & 1.7703 & 2.3805 & & 28 & 3.4665 & .88575 & 3.5000 & 3.1230 & 3.8099 & \\
\hline & South & 76 & 1.7615 & .94069 & 1.2778 & 1.5465 & 1.9764 & & 76 & 3.3056 & .74413 & 3.2083 & 3.1356 & 3.4757 & \\
\hline & East & 25 & 1.9350 & .92176 & 1.5000 & 1.5546 & 2.3155 & & 25 & 3.2158 & .85364 & 3.0833 & 2.8634 & 3.5681 & \\
\hline & West & 44 & $1.3313^{*}$ & .660 & 1.0556 & 1.0843 & 1.5782 & & 44 & $3.8537^{*}$ & 1.21370 & 3.8333 & 3.4847 & 4.2227 & \\
\hline & Total & 219 & & & & & & & 219 & & & & & & \\
\hline \multirow{7}{*}{$\underset{4}{\mathscr{~}}$} & $24-30$ & 112 & 1.6460 & .87187 & 1.1667 & 1.4828 & 1.8093 & \multirow{6}{*}{0.075} & 112 & $3.2058^{*}$ & .76807 & 3.1333 & 3.0620 & 3.3496 & \multirow{6}{*}{0.000} \\
\hline & $31-35$ & 52 & 1.6375 & .59162 & 1.4722 & 1.4728 & 1.8022 & & 52 & $3.2582^{*}$ & .90617 & 3.1250 & 3.0059 & 3.5104 & \\
\hline & $36-40$ & 30 & 2.1223 & 1.19088 & 1.6111 & 1.6776 & 2.5669 & & 30 & 3.7419 & 1.02267 & 3.6591 & 3.3600 & 4.1238 & \\
\hline & 41-45 & 9 & 1.6358 & .81560 & 1.1667 & 1.0089 & 2.2627 & & 9 & 3.5833 & 1.62660 & 4.0000 & 2.3330 & 4.8337 & \\
\hline & $46-50$ & 8 & 1.8472 & 1.44894 & 1.1667 & .6359 & 3.0586 & & 8 & 3.8229 & 1.45599 & 4.2500 & 2.6057 & 5.0402 & \\
\hline & $>50$ & 8 & 1.8681 & 1.61779 & 1.0000 & .5156 & 3.2206 & & 8 & 4.4896 & .93694 & 5.0000 & 3.7063 & 5.2729 & \\
\hline & Total & 219 & & & & & & & 219 & & & & & & \\
\hline \multirow{3}{*}{ 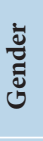 } & Male & 139 & 1.6713 & .83904 & 1.3333 & 1.5306 & 1.8120 & \multirow{2}{*}{0.617} & 139 & 3.2651 & .87782 & 3.1667 & 3.1178 & 3.4123 & \multirow{2}{*}{0.04} \\
\hline & Female & 80 & 1.8164 & 1.06534 & 1.3333 & 1.5793 & 2.0535 & & 80 & 3.5705 & 1.05936 & 3.5000 & 3.3347 & 3.8062 & \\
\hline & Total & 219 & & & & & & & 219 & & & & & & \\
\hline \multirow{6}{*}{ 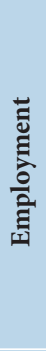 } & $\begin{array}{l}\text { Director of } \\
\text { Pharmacy }\end{array}$ & 15 & 1.2526 & .33080 & 1.0667 & 1.0694 & 1.4358 & \multirow{5}{*}{0.391} & 15 & 3.4960 & 1.14681 & 3.3333 & 2.8609 & 4.1310 & \multirow{5}{*}{0.003} \\
\hline & $\begin{array}{l}\text { Assistant director } \\
\text { of Pharmacy }\end{array}$ & 16 & 1.4516 & .38621 & 1.3889 & 1.2458 & 1.6574 & & 16 & 3.3755 & 1.23588 & 3.0417 & 2.7169 & 4.0340 & \\
\hline & Supervisor & 33 & 2.2586 & 1.39862 & 1.9444 & 1.7626 & 2.7545 & & 33 & $3.8402^{*}$ & 1.03108 & 3.9167 & 3.4746 & 4.2058 & \\
\hline & Pharmacy staff & 113 & 1.6401 & .75537 & 1.3333 & 1.4994 & 1.7809 & & 113 & 3.2849 & .89960 & 3.0833 & 3.1172 & 3.4526 & \\
\hline & Intern & 42 & 1.8032 & 1.01934 & 1.1667 & 1.4855 & 2.1208 & & 42 & 3.2170 & .77176 & 3.2083 & 2.9765 & 3.4575 & \\
\hline & Total & 219 & & & & & & & 219 & & & & & & \\
\hline \multirow{7}{*}{ 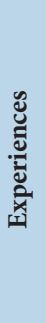 } & $<1$ & 55 & 1.7881 & 1.01949 & 1.0556 & 1.5125 & 2.0637 & \multirow{6}{*}{0.336} & 55 & 3.3606 & .78617 & 3.3333 & 3.1481 & 3.5731 & \multirow{6}{*}{0.001} \\
\hline & $1-3$ & 64 & 1.7388 & .76370 & 1.5000 & 1.5480 & 1.9296 & & 64 & 3.2225 & .89886 & 3.2159 & 2.9980 & 3.4471 & \\
\hline & $4-6$ & 43 & 1.4997 & .60201 & 1.3333 & 1.3144 & 1.6850 & & 43 & 3.1989 & .75534 & 3.0000 & 2.9665 & 3.4314 & \\
\hline & $7-9$ & 27 & 1.8744 & 1.09126 & 1.4444 & 1.4427 & 2.3061 & & 27 & 3.4279 & 1.09603 & 3.2727 & 2.9943 & 3.8615 & \\
\hline & $10-12$ & 13 & 1.6797 & 1.00756 & 1.2222 & 1.0709 & 2.2886 & & 13 & $4.3765^{\star}$ & .98215 & 5.0000 & 3.7829 & 4.9700 & \\
\hline & $>12$ & 17 & 1.8268 & 1.44536 & 1.0000 & 1.0837 & 2.5699 & & 17 & 3.6119 & 1.40944 & 3.5000 & 2.8872 & 4.3365 & \\
\hline & Total & 219 & & & & & & & 219 & & & & & & \\
\hline
\end{tabular}




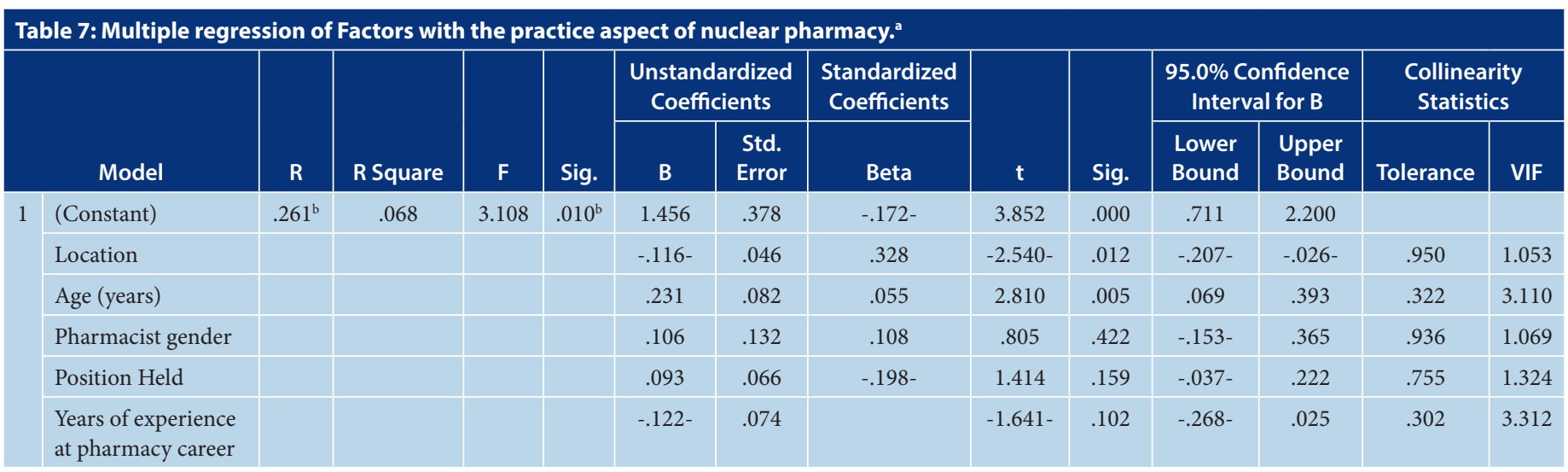

a. Dependent Variable: practice aspect of nuclear pharmacy, ${ }^{\mathrm{b}}$ Predictors: (Constant), Location, Age (years), Pharmacist gender, Position Held, and Years of experiences at pharmacy career.

\begin{tabular}{|c|c|c|c|c|c|c|c|}
\hline \multicolumn{8}{|c|}{ Bootstrap for Coefficients } \\
\hline & \multirow{2}{*}{ Model } & \multirow{2}{*}{ B } & \multicolumn{5}{|c|}{ Bootstrap ${ }^{a}$} \\
\hline & & & Bias & Std. Error & Sig. (2-tailed) & \multicolumn{2}{|c|}{$95 \%$ Confidence Interval } \\
\hline \multirow[t]{4}{*}{1} & (Constant) & 1.456 & .003 & .331 & .001 & .799 & 2.105 \\
\hline & Location & $-.116-$ & .000 & .049 & .023 & $-.214-$ & $-.022-$ \\
\hline & Position Held & .093 & .001 & .053 & .076 & $-.018-$ & .201 \\
\hline & Years of experience at pharmacy career & $-.122-$ & .001 & .068 & .081 & $-.244-$ & .028 \\
\hline
\end{tabular}

a. Unless otherwise noted, bootstrap results are based on 1000 bootstrap samples

$p=0.000$ ) between the implementation of nuclear pharmacy and factors affecting it. However, three factors were found to affect the responses: first, location of the pharmacists explained $16.9 \%(p=0.010)$ of the variation; second, age explained $41.6 \%(p=0.000)$ of the positive relationship; and finally, years of work experience explained $25.7 \% \quad(p=0.27)$ of the negative association in the practice of implementation of nuclear pharmacy with a statistically significant $(p<0.05)$ through multiple regression model and confirmed by Bootstrap model. The relationship between the practice aspect of nuclear pharmacy and two factors verified by the nonexistence of multicollinearity with location factor (Variance Inflation factors $\mathrm{VIF}=1.053)$, age $(\mathrm{VIF}=3.11)$, and experiences $(\mathrm{VIF}=3.312)$ all of them almost less than three or less than five ${ }^{[25-27]}$ (Table 8).

\section{DISCUSSION}

The practice of nuclear medicine was started at a single center in 1983, which expanded to more than 50 healthcare organizations in Saudi Arabia. ${ }^{[12,13,18]}$ Nuclear medicine is mainly used for diagnostic procedures and the management of various diseases. ${ }^{[12,13,18]}$ In contrast, the nuclear pharmacy includes procurement, storage, preparation of parenteral or nonparenteral radioactive medications, and follow-up with emergency safety and efficacy. Various physicians and technicians have specialized in nuclear medicine. However, only a few pharmacists work in the department of nuclear medicine in Saudi Arabia, ${ }^{[12,13]}$ which is lower than in other countries. ${ }^{[12]}$ Therefore, it was unclear the activities of pharmacists at nuclear medicine or nuclear pharmacy practice. Thus, in this study, we aimed to declare the practice of nuclear pharmacy at healthcare centers. This cross-sectional study was performed with a target-convenient sample through a validated electronic survey and highreliability scores. The sample consisted of males from the southern region of Saudi Arabia based on the survey distributed by participant's authors. The responders were young with less work experience and low position held. However, the young pharmacists responded to the research survey better than that the old pharmacists. Usually, the new pharmacist graduate worked at outpatient and inpatient pharmacies as results explored.

According to the results of this study, the implementation of nuclear pharmacy practice was deficient. The element with the highest score of practice was the preparation area and facilities. The pharmacy services established the appropriate place for drug distribution. They did not provide nuclear medication at many healthcare organizations due to the expensive radiopharmaceutical products or the absence of trained nuclear pharmacists. ${ }^{[2]}$ The pharmacist seldom monitors radioactive safety, and drug-related problems as the majority of the healthcare centers do not provide nuclear pharmacies. The vision, mission, and annual plan did not exist at most healthcare centers because the nuclear pharmacy domains were still not established. ${ }^{[1]}$ Another very critical foundation activity was asked the pharmacist in the survey about nuclear pharmacy performance. According to our results, almost two-thirds of the responders had no experience practicing in the nuclear pharmacy field. There are no differences in answering the survey between practice or did not practice nuclear pharmacy. The pharmacists might be practice in reality. There are no actual nuclear pharmacy services, the pharmacist did not understand the survey very well, or the responders did not answer properly. The finding showed that pharmacists are willing to involve as active members at nuclear pharmacy services to provide full clinical and distributive nuclear pharmacy activities. ${ }^{[29,30,31]}$ Moreover, 


\begin{tabular}{|c|c|c|c|c|c|c|c|c|c|c|c|c|c|c|}
\hline & \multirow[b]{2}{*}{ Model } & \multirow[b]{2}{*}{$\mathbf{R}$} & \multirow[b]{2}{*}{ R Square } & \multirow[b]{2}{*}{$\mathbf{F}$} & \multirow[b]{2}{*}{ Sig. } & \multicolumn{2}{|c|}{$\begin{array}{c}\text { Unstandardized } \\
\text { Coefficients }\end{array}$} & \multirow{2}{*}{$\begin{array}{c}\begin{array}{c}\text { Standardized } \\
\text { Coefficients }\end{array} \\
\text { Beta }\end{array}$} & \multirow[b]{2}{*}{$\mathbf{t}$} & \multirow[b]{2}{*}{ Sig. } & \multicolumn{2}{|c|}{$\begin{array}{c}95.0 \% \text { Confidence } \\
\text { Interval for B }\end{array}$} & \multicolumn{2}{|c|}{$\begin{array}{c}\text { Collinearity } \\
\text { Statistics }\end{array}$} \\
\hline & & & & & & B & $\begin{array}{l}\text { Std. } \\
\text { Error }\end{array}$ & & & & $\begin{array}{l}\text { Lower } \\
\text { Bound }\end{array}$ & $\begin{array}{l}\text { Upper } \\
\text { Bound }\end{array}$ & Tolerance & VIF \\
\hline \multirow[t]{6}{*}{1} & (Constant) & $.373^{\mathrm{b}}$ & .139 & 6.883 & $.000^{\mathrm{b}}$ & 2.835 & .374 & & 7.572 & .000 & 2.097 & 3.573 & & \\
\hline & Location & & & & & .118 & .045 & .169 & 2.595 & .010 & .028 & .207 & .950 & 1.053 \\
\hline & Age (years) & & & & & .303 & .082 & .416 & 3.712 & .000 & .142 & .463 & .322 & 3.110 \\
\hline & Pharmacist gender & & & & & .181 & .130 & .091 & 1.387 & .167 & $-.076-$ & .438 & .936 & 1.069 \\
\hline & Position Held & & & & & $-.057-$ & .065 & $-.064-$ & $-.881-$ & .380 & $-.185-$ & .071 & .755 & 1.324 \\
\hline & $\begin{array}{l}\text { Years of experience } \\
\text { at pharmacy career }\end{array}$ & & & & & $-.163-$ & .074 & $-.257-$ & $-2.221-$ & .027 & $-.308-$ & $-.018-$ & .302 & 3.312 \\
\hline
\end{tabular}

a. Dependent Variable: practice aspect of nuclear pharmacy, ${ }^{\mathrm{b}}$ Predictors: (Constant), Location, Age (years), Pharmacist gender, Position Held, and Years of experiences at pharmacy career.

\begin{tabular}{|c|c|c|c|c|c|c|c|}
\hline \multicolumn{8}{|c|}{ Bootstrap for Coefficients } \\
\hline & \multirow[b]{3}{*}{ Model } & \multirow[b]{3}{*}{ B } & \multicolumn{5}{|c|}{ Bootstrapa } \\
\hline & & & \multirow[b]{2}{*}{ Bias } & \multirow[b]{2}{*}{ Std. Error } & \multirow[b]{2}{*}{ Sig. (2-tailed) } & \multicolumn{2}{|c|}{$\mathbf{9 5} \%$ Confidence Interval } \\
\hline & & & & & & Lower & Upper \\
\hline \multirow[t]{6}{*}{1} & (Constant) & 2.835 & .002 & .451 & .001 & 1.949 & 3.721 \\
\hline & Location & .118 & $-.002-$ & .046 & .008 & .023 & .205 \\
\hline & Age (years) & .303 & $-.001-$ & .080 & .001 & .141 & .456 \\
\hline & Pharmacist gender & .181 & .001 & .139 & .205 & $-.088-$ & .459 \\
\hline & Position Held & $-.057-$ & .000 & .072 & .422 & $-.200-$ & .088 \\
\hline & Years of experience at pharmacy career & $-.163-$ & .001 & .072 & .021 & $-.308-$ & $-.028-$ \\
\hline
\end{tabular}

a. Unless otherwise noted, bootstrap results are based on 1000 bootstrap samples

to successfully operate nuclear pharmacy services, two main things need to be done in nuclear pharmacy practice: nuclear pharmacy utilization and outsourcing. These aspects were beneficial and might be cheaper than established inside healthcare organizations. ${ }^{[32,33]}$ Some of the crucial elements were not implemented in the nuclear pharmacy practice, such as education and training for nuclear pharmacy. The pharmacy resources are not available at most healthcare centers, and computerized physicians order entry of the nuclear pharmacy services or radioactive drug, which were consisted of a previous nuclear medicine study finding. ${ }^{[13]}$ Therefore, the responders are highly recommended to be pharmacists or clinical pharmacists responsible for nuclear pharmacy practice. At the same time, the responsibility of the nuclear pharmacy should be withdrawn from physicians because the pharmacist should be more familiar with radiopharmaceutical drugs from their procurement, preparation, and dispensing stages. $^{[34]}$ Moreover, nuclear pharmacists provide clinical activities to the patients. ${ }^{[29-31,33,35-37]}$ Despite all the previous positive answers, the majority of the responders of nuclear pharmacy practice did not participate in this study. Thus, our results showed no difference between the practice of nuclear pharmacy services because of the small sample size.

Many factors affected nuclear pharmacy practice. For instance, location, age, gender, position, and years of experience. All these factors did not affect nuclear pharmacy practice in a statistically significant manner $(p>0.05)$. However, one factor that might affect the practice of nuclear pharmacy services was the location of the pharmacist. The western region was affected by nuclear pharmacy practice because several nuclear pharmacy services are not widely practiced in a particular area. On the contrary, five factors might affect the implementation of pharmacy practice aspect. First, the western region was significantly affected responders answered. That is related to some parts of nuclear pharmacy practice not being done, the responders not understanding the questions or unclear justifications. Second, the young pharmacists might affect the nuclear pharmacy implementation because they do not have enough experience in the field of nuclear pharmacy practice. Third, females agreed more on nuclear pharmacy practice than males because females primarily practice in this field than males. Fourth, the supervisor (position held) had the highest score of nuclear pharmacy implementation, which is expected because they had more experience in pharmacy administration or pharmacy quality management during accreditation of legal bodies. Finally, work experience is a critical factor that affects the nuclear pharmacy practice. Especially in our study, 10-12 years of experience needed more practice in nuclear pharmacy.

The pharmacy aspect of nuclear pharmacy showed a significant positive correlation with the location and age of the pharmacists, which is expected. The changes in the area from one region to another will increase practice experiences because of the nuclear pharmacy services offered at this location or region. In addition, the age of the pharmacist had a positive correlation with the responses. Higher age showed higher scores in practice, and they had more training and experience. Therefore, the nuclear pharmacy practice implementation is affected by two factors: location and age of the pharmacist. Moreover, several years of experience is an additional factor that affected the responses.

\section{LIMITATIONS}

This study provides critical information about nuclear pharmacy implementation. 
However, there were some limitations. First, the calculated sample size did not reach an optimal level. Further analysis with at least $380-400$ responders is highly recommended. Second, the method of sampling was the convenient sample due to which the sample contained unequal distribution of responders per geographic location, and there was unequal age distribution. Third, the number of male and female responders was unequal. Fourth, most of the responders were young who had recently graduated with little experience in nuclear pharmacy practice. As a result, our results did not reflect pharmacists with different levels of experience, age groups, or positions. Further studies with comparable demographic data are highly recommended. Finally, literature is scarce concerning research about nuclear pharmacy practice, and therefore, we could compare our data with previous investigations.

\section{CONCLUSION}

The practice of nuclear pharmacy in Saudi Arabia is poor, which could be due to various factors that influenced the implementation of nuclear pharmacy, such as young age. On the other hand, more experience or higher position as the supervisor showed good pharmacists' knowledge in terms of practice. Therefore, nuclear pharmacists should be increased and involved in nuclear medicine with a clear job description. Further in-depth survey about nuclear pharmacy services is required, and strategic plans should be set up to improve nuclear pharmacy practice in Saudi Arabia.

\section{ACKNOWLEDGEMENT}

None.

\section{CONFLICT OF INTEREST}

The authors declare that there is no conflict of interest.

\section{Funding}

None

\section{Consent for Publications}

Informed consent was obtained from all the participants

\section{Ethical Approval}

This research was exempted from research and ethical committee or an institutional review board (IRB) approval.

https://www.hhs.gov/ohrp/regulations-andpolicy/decision-charts-2018/index.html

\section{ABBREVIATIONS}

KSA: Kingdom of Saudi Arabia; UPS: United Stare Pharmacopeia; SPSS: Statistical Package of Social Sciences; JASP: Jeffery's Amazing Statistics Program; Strobe: Strengthening the reporting of observational studies in epidemiology statement: guidelines for reporting observational studies.

\section{ORCID ID}

Yousef Ahmed Alomi https://orcid.org/ 0000-0003-1381-628X

\section{REFERENCES}

1. Kastango ES, American Society of Health-System Pharmacists (ASHP). Blueprint for implementing USP chapter 797 for compounding sterile preparations. Am J Health Syst Pharm. 2005;62(12):127188. doi: 10.1093/ajhp/62.12.1271, PMID 15947127.

2. Pharmacopeia US. <797> Pharmaceutical compounding - sterile preparations [internet]. p. 1-61; 2008. The United States pharmacopeial convention. Available from: https://www.sefh.es/ fichadjuntos/USP797GC.pdf [cited 19/8/2021].

3. Kienle PC. Compounding nonsterile preparations: USP <795> and <800>. Pharm Today. 2017;23(10):56-72. doi: 10.1016/j.ptdy.2017.09.010.

4. United States Pharmacopeia. USP general chapter $<800>$ hazardous drugs- handling in healthcare settings. The United States pharmacopeial convention; 2017. p. 1-20.

5. United States Pharmacopia. USP general chapter $<825>$ radiopharmaceuticals - preparation, compounding, dispensing, and repackaging. U S Pharmacopia. 2019:1-29://www.

6. Saudi food and drug authority. Guidelines for good Manufacturing Practice of Radiopharmaceuticals version 1.2; 2010

7. Elsinga P, Todde S, Penuelas I, Meyer G, Farstad B, Faivre-Chauvet A, Mikolajczak R, Westera G, Gmeiner-Stopar T, Decristoforo C, Radiopharmacy Committee of the EANM. Guidance on current good radiopharmacy practice (cGRPP) for the small-scale preparation of radiopharmaceuticals. Eur J Nucl Med Mol Imaging. 2010;37(5):1049-62. doi: 10.1007/s00259-010-1407-3, PMID 20306035.

8. Hung JC, Augustine SC, Cheng KT, Green RL, Hopkins WM, Laven DL, Nelson BR, Petry NA, Ponto JA, Quinton TM, Swanson DP. Explanations and unresolved issues pertaining to the development of the Nuclear Pharmacy Compounding Guidelines [internet]. J Am Pharm Assoc (Wash). 2002;42(5):789-98. doi: 10.1331/108658002764653568, PMID 12269713.

9. Chilton HM. The Joint Commission (JCAHO) and nuclear pharmacy. J Pharm Pract. 1989;2(5):302-5. doi: $10.1177 / 089719008900200508$.

10. Hammes RJ, Laven DL, Catizone C. Nuclear Pharmacy and the National Association of Boards of Pharmacy (NABP). J Pharm Pract. 1989; 2(5):314-21. doi: 10.1177/089719008900200510.

11. Ponto JA, Hung JC. Nuclear pharmacy, Part II: Nuclear pharmacy practice today. J Nucl Med Technol. 2000;28(2):76-81; quiz 83. PMID 10824617.

12. Paez $D$, Becic $T$, Bhonsle $U$, Jalilian $A R$, Nuñez-Miller R, Osso JA. Current status of nuclear medicine practice in the middle east. Semin Nucl Med. 2016;46(4):265-72. doi: 10.1053/j. semnuclmed.2016.01.005, PMID 27237437.

13. Hussein A, Farghaly $H$, Nasr $H$. Current situation of nuclear medicine in Saudi Arabia. Int J Sci Res. 2019;8(11):1-3.

14. Al-Haj AN, Lobriguito AM, Al Anazi I. Radioactive waste handling and disposal at king Faisal specialist hospital and research centre. Health Phys. 2012;103(2);Suppl 2:S144-50. doi: 10.1097/ HP.0b013e318254543e, PMID 22739968.

15. Basmadjian GP, Johnston J, Barker K, Ice RD. Trends in radiopharmaceutical dispensing in a regional nuclear pharmacy. Am J Hosp Pharm 1982;39(11):1933-6. doi: 10.1093/ajhp/39.11.1933, PMID 7148864.

16. Brasil MP, De Barros MP, Antunes LJ, Santos-Oliveira R. Hospital nuclear pharmacy survey: preliminary aspects in Brazil. JYoung Pharm. 2012;4(4):279-81. doi: 10.4103/0975-1483.104373, PMID 23493051.

17. Barnett CW, Kavula MP. Nuclear pharmacy in the community setting: an assessment of employment conditions and job satisfaction. J Pharm Pract. 1992;5(1):57-64. doi: 10.1177/089719009200500110.

18. Cyclotron \& radiopharmaceuticals. King Faisal Specialist Hospital \& Research Centre [internet] [cited May 23 2021]. Available from: https://www. kfshrc.edu.sa/en/home/research/departments/ cyclotronradiopharmaceuticals.

19. Charan J, Biswas T. How to calculate sample size for different study designs in medical research? Indian J Psychol Med. 2013;35(2):121-6. doi: 10.4103/0253-7176.116232, PMID 24049221.

20. Pourhoseingholi MA, Vahedi M, Rahimzadeh $M$. Sample size calculation in medical studies. Gastroenterol Hepatol Bed Bench. 2013;6(1):14-7. PMID 24834239

21. Ezhumalai DG. How Big A Sample Do I Require? Annals of SBV. 2017;6(1):39-41. doi: 10.5005/jpjournals-10085-6113

22. Johnson TP, Wislar JS. Response rates and nonresponse errors in surveys [internet] JAMA. 2012;307(17):1805-6. doi: 10.1001/ jama.2012.3532, PMID 22550194.

23. von Elm E, Altman DG, Egger M, Pocock SJ, Gøtzsche PC, Vandenbroucke JP. The strengthening the reporting of observational studies in epidemiology (STROBE) statement: guidelines for reporting observational studies. PLOS Med. 2007;4(10):1623-7. doi: 10.1371/journal.pmed.0040296.

24. Von Elm E, Altman DG, Egger M, Pocock SJ, Gøtzsche PC, Vandenbroucke JP. The Strengthening the Reporting of Observational Studies in Epidemiology (STROBE) statement: guidelines for reporting observational studies [internet]. Vol. 370; 2007. Available from: http://www.thelancet. com. Available from: http://www.plosmedicine.org.

25. Liao D, Valliant R. Variance inflation factors in the analysis of complex survey data. Surv Methodol. 2012;38(1):53-62

26. Akinwande MO, Dikko HG, Samson A. Variance inflation Factor: as a condition for the inclusion of suppressor variable(s) in regression analysis. Open J Stat. 2015;05(7):754-67. doi: 10.4236/ ojs.2015.57075.

27. Thompson CG, Kim RS, Aloe AM, Becker BJ. Extracting the Variance In flation Factor and Other Multicollinearity Diagnostics from Typical Regression Results. Basic Appl Soc Psych. 2017;39(2):81-90. doi: 10.1080/01973533.2016.1277529.

28. Al Ahmed A, Al-Surimi K. Improving efficiency management of radiopharmaceutical materials at a nuclear medicine department. BMJ Qual Improv Rep. 2015;4(1):u208970. doi: 10.1136/bmjquality. u208970.w3709, PMID 26734451.

29. Sagir O, Erdogan S, Ozer Y. A new area of pharmacy profession in Turkey in the 21st century: nuclear pharmacy (Radiopharmacy). J Sci Technol. 2005; 1:25-9.

30. Laven DL, Martin WR. Justification for hospitalbased nuclear pharmacy services. J Pharm Pract. 1989;2(3):152-61. doi: 10.1177/089719008900200304.

31. Patel J, Bhatt S. Clinical pharmacist in nuclear medicine: A new role in ascendancy. IJOPP. 2014;7(3):14-8. doi: 10.5530/ijopp.7.3.4

32. Callahan RJ. The role of commercial nuclear pharmacy in the future practice of nuclear medicine. Semin Nucl Med. 1996;26(2):85-90. doi: 10.1016/ s0001-2998(96)80029-8, PMID 8723502.

33. Callahan RJ, Dragotakes SC. The role of the practice of nuclear pharmacy in positron 
emission tomography. Clin Positron Imaging. 1999;2(4):211-6. doi: 10.1016/s1095-0397(99)000229, PMID 14516532.

34. Dansereau RN, Dansereau RJ. Hospital nuclear pharmacy - a comparison of physician and pharmacist practice. Ann Pharmacother. 1992; 26(6):826-8. doi: 10.1177/106002809202600615, PMID 1611167
35. Alsharef S, Alanazi M, Alharthi F, Qandil D, Qushawy M. Review about radiopharmaceuticals: preparation, radioactivity, and applications. Int J Appl Pharm. 2020;12(3):8-15.

36. Parasuraman S, Mueen Ahmed KK, Bin Hashim TS, Muralidharan S, Kumar KJ, Ping WY, Syamittra $B$, Dhanaraj SA. Knowledge about the availability of the pharmacist in the Nuclear Medicine
Department: A questionnaire-based study among health-care professionals. J Basic Clin Pharm. 2014;6(1):19-23. doi: 10.4103/0976-0105.145773. PMID 25538467

37. Gregorio N, Hladik WB, Kavula MP. The nuclear pharmacist as a consultant and drug information specialist. J Pharm Pract. 1989;2(5):284-6. doi: 10.1177/089719008900200505. 